\title{
Femoral intraosseous rhabdomyosarcoma: a case report and literature review
}

\section{Rabdomiossarcoma intraósseo femoral: relato de caso e revisão da literatura}

Dan Carai Maia Viola1,2,3® , Nathalia Sundin Palmeira de Oliveira ${ }^{1,2}$, Jairo Greco Garcia1,2, Marcelo de Toledo Petrilli ${ }^{1,2}$, Carla Renata Pacheco Donato Macedo ${ }^{4}$, Maria Teresa Seixas Alves ${ }^{5}$, Reynaldo JesusGarcia ${ }^{1,2,3}$

\begin{abstract}
Introduction: Rhabdomyosarcoma is the most common soft tissue sarcoma in childhood. However, primary bone rhabdomyosarcoma is a rare entity with some few cases reported. Case Report: We present a case of a 19-year-old female patient referred from another service with three months history of a bone tumor on the femur. The first anatomopathological study was consistent with high-grade osteogenic sarcoma. After revision exams and analysis of surgically resected tumor, the primary osseous rhabdomyosarcoma was confirmed. The patient had undergone tumor resection and reconstruction with mega prosthesis. After surgery, she received chemotherapy following rhabdomyosarcoma protocol. Conclusion: Primary osseous rhabdomyosarcoma is a rare but important differential diagnosis to be thought on atypical presentation of primary bone sarcomas.
\end{abstract}

Keywords: Rhabdomyosarcoma, Bone Neoplasma, Chemotherapy

\footnotetext{
1. Universidade Federal De Sao Paulo, Ortopedia E Traumatologia - Sao Paulo - SP - Brazil

2. Instituto De Oncologia Pediatrica / lop-Graacc, Ortopedia Oncologica - Sao Paulo - SP - Brazil

3. Hospital Israelita Albert Einstein

4. Instituto De Oncologia Pediatrica / lop-Graacc, Oncologia Pediatrica - Sao Paulo - SP - Brazil

5. Universidade Federal De Sao Paulo, Patologia - Sao Paulo - SP - Brazil

Financial support: none to declare.

Conflicts of interest: The authors declare no conflict of interest relevant to this manuscript.

Correspondence author: Dan Carai Maia Viola

E-mail:dcmviola@gmail.com / danc@einstein.br
} 


\begin{abstract}
RESUMO
Introdução: Rabdomiossarcoma é o sarcoma de partes moles mais comum na infância. No entanto, o rabdomiossarcoma ósseo primário é uma entidade rara com alguns poucos casos relatados. Relato de Caso: Apresentamos o caso de uma paciente do sexo feminino, 19 anos, encaminhada de outro serviço, com história de tumor ósseo em fêmur há três meses. O primeiro estudo anatomopatológico foi compatível com sarcoma osteogênico de alto grau. Após exames de revisão e análise do tumor ressecado cirurgicamente, foi confirmado o rabdomiossarcoma ósseo primário. A paciente havia sido submetida à ressecção tumoral e reconstrução com mega prótese. Após a cirurgia, ela recebeu quimioterapia seguindo o protocolo de rabdomiossarcoma. Conclusão: Rabdomiossarcoma ósseo primário é um diagnóstico diferencial raro, mas importante a ser pensado na apresentação atípica do sarcoma ósseo primário.
\end{abstract}

Descritores: Rabdomiossarcoma, Neoplasia ossea, Quimioterapia

\section{INTRODUCTION}

Rhabdomyosarcoma (RMS) is the most common soft tissue sarcoma of childhood, corresponding $4.5 \%$ of all childhood malignancies ${ }^{(1,2)}$ with approximately 250 new cases per year in the United States of America. ${ }^{(3)}$

RMS is a high-grade malignant tumor of mesenchymal origin and is part of the group of small, round azurophilic neoplasms such as neuroblastoma, lymphoma, and tumors of the Ewing family. There are four recognized histological types, and these have prognostic value for the disease: 1) alveolar (ARMS); 2) embryonic (ERMS); 3) pleomorphic; 4) sclerotic/ spindle cell. ${ }^{(4)}$ The pleomorphic and spindle cell sclerosing subtypes are the most common variants in adults. ${ }^{(3)}$

The different levels of atypia of rhabdomyoblasts are a hallmark of the tumor. In immunohistochemistry, positivity for the expression of the protein MyoD1, myogenin (Myf4), desmin and muscle-specific actin are important for the diagnosis..$^{(3,5)}$

The bone lesion of RMS is most often as metastatic lesions or direct invasion from soft tissue adjacent mass. These lesions are usually small in comparison to the primary bone tumors or soft tissue tumors. Otherwise, primary bone lesions usually demonstrate more bone destruction and a bigger size. Primary bone RMS is characterized by bone damage without the identification of a primary soft tissue tumor or by a soft tissue component that is typically due to invasion by the primary intraosseous tumor. ${ }^{(6)}$

Imaging studies of intraosseous RMS are non-specific and difficult to differentiate from other sarcomas. The tumor usually presents an osteolytic appearance on radiographs. It may have an isointense appearance with the adjacent musculature at T1 weighted MRI and hyperintense appearance at T2. The alveolar and pleomorphic subtypes may have areas of hemorrhage and necrosis. Post-contrast se- ries shows an unspecific enhanced signal. This set of characteristics is common to a variable range of sarcomas and not specific for RMS diagnosis. ${ }^{(7)}$

Currently, the recommended treatment for RMS is multimodal with surgery, chemotherapy, and radiotherapy. The survivorship with this kind of treatment on children with localized disease may be greater than $60 \%$. However, the 2-year survival rate of patients with pleomorphic RMS, mostly adults, remains below 30\%.(2)

We found fourteen cases of primary bone RMS reported in the literature. This work aims to present a new case of intraosseous rhabdomyosarcoma and carry out a bibliographic review of the current literature.

The patient was informed that data concerning the case would be submitted for publication. She has consented and made a formal consent term.

\section{CASE REPORT}

We present a case of a 19-year-old female patient referred from another service with three months complain of progressive pain in the left thigh associated with an increase in diameter. She did not have any positive history for previous diseases and no familiar history for oncological diseases.

The physical exam was unremarkable except by a palpable and painful mass on the left tight, without alteration on neurological and vascular functions in the limb.

The radiographic study showed a lytic lesion in the distal third of femur diaphysis with rupture of the medial cortical. The X-ray image was compatible with the differential diagnosis of primary malignant bone tumors and the main hypothesis was of osteogenic sarcoma (Figure 1).

The patient underwent systemic and local staging. The tests were negative for metastatic disease. Magnetic resonance imaging (MRI) showed an intramedullary mass with medial femoral cortex disruption 


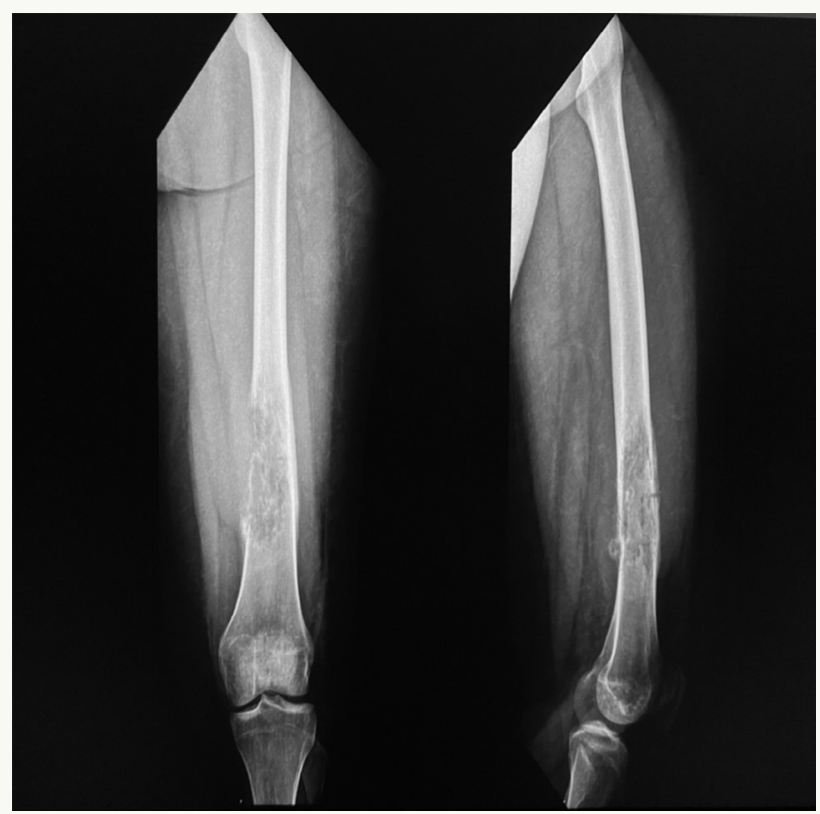

Figure 1. Radiographic image showing lytic lesion on femoral distal diaphysis with medial cortical rupture.

and an important soft tissue component, without vascular involvement (Figure 2). Despite the protection with the use of crutches, the patient developed a pathological fracture one week after staging exams, while moving in bed (low-energy trauma).

Upon arrival at our service, the patient had already undergone a needle biopsy. The anatomopathological report was suggestive of high-grade osteosarcoma.

The surgical anatomopathological study showed an infiltrative sarcoma of spindle cells with a high proliferation rate, without osteoid production. The morphological aspect highlighted by the expression of desmin and the positivity of myogenin has supported the diagnosis of rhabdomyosarcoma. Figures 3 and 4 shows hematoxylin-eosin (H\&E) stain. Table 1 and Figures 5 and 6 represent the immunohistochemistry panel.

The treatment chemotherapy protocol for highgrade non-metastatic osteosarcoma was started (cisplatin, doxorubicin, and methotrexate). ${ }^{(8)}$ After 14 weeks, was performed the tumor local control with diaphyseal femoral resection and reconstruction with a mega prosthesis.

The anatomopathological analysis of the surgical specimen showed a good response to the chemotherapy treatment containing less than $10 \%$ viable tumor, non-reactive neoplasia, and margins free of disease. Adjuvant chemotherapy was modified for a new diagnosis based on the pathological review and surgical resection analysis. Post-operative chemotherapy was performed with four cycles of ifosfamide and etoposide intercalated with vincristine, dactinomycin, and cyclophosphamide (VAC). After the third cycle of chemotherapy, a patient underwent adjuvant radiotherapy with the inclusion of the entire length of the surgical site (total dose of 50 Grays).

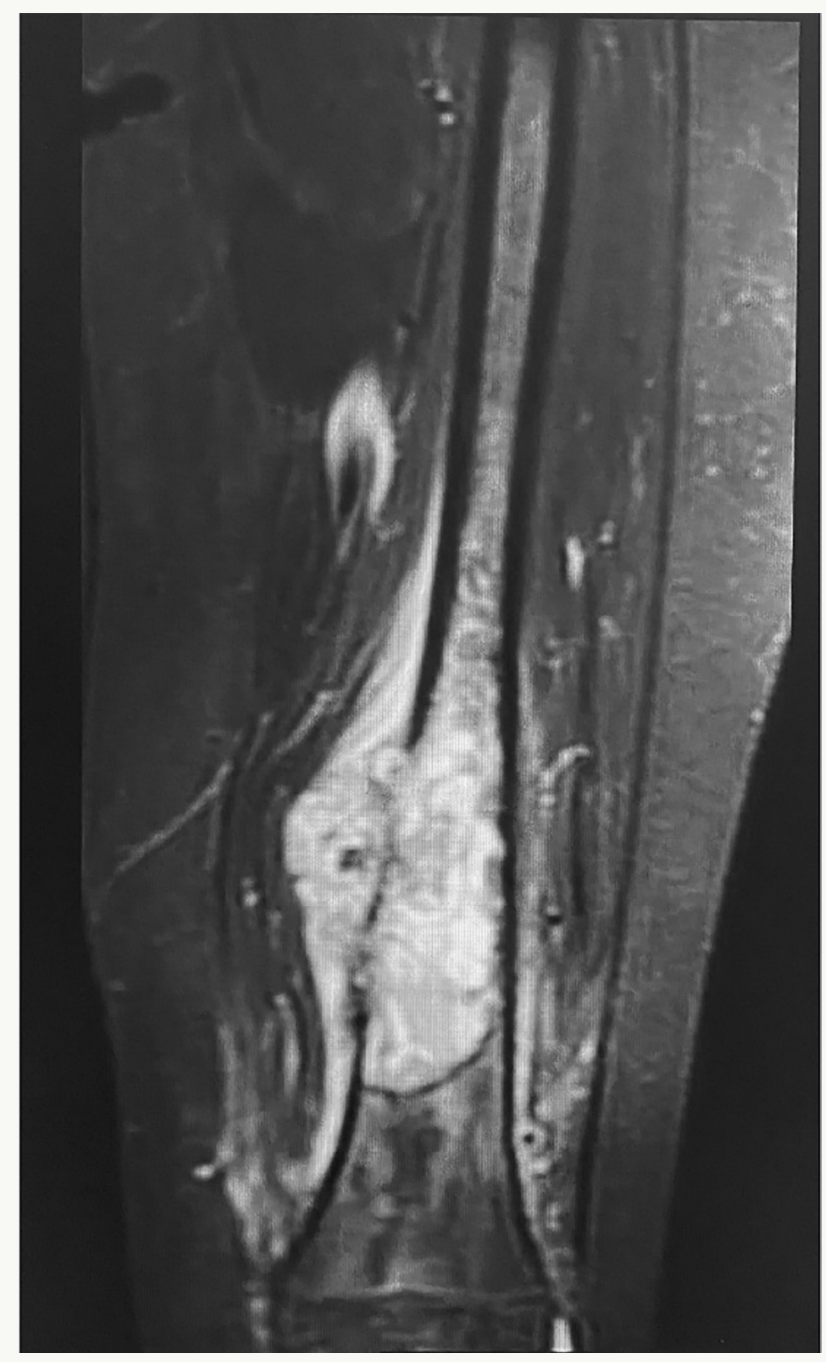

Figure 2. MRI image showing intramedullary lesion with hypersignal T2-weighetd with cortical rupture and extra-bone mass.

The patient evaluated well, with no operative complications until then (15 months postoperative follow-up). After the motor rehabilitation period, she uses crutches for walking long distances. The patient keeps in an orthopedic and oncological postoperative follow-up, with a current disease-free status.

\section{DISCUSSION}

The literature review has shown few reports of primary bone RMS.(1,7,9-18) Of the fifteen cases presented so far (including this one), two did not have a specified subtype and one of them did not give access to full data (Table 2). The ERMS and ARMS subtypes were concentrated in younger patients while all pleomorphic subtypes were diagnosed in patients over 30-years-old. There were no reports of intraosseous RMS of the sclerosing subtype.

Pathological fracture is frequently found on bone rhabdomyosarcoma. We found 14 cases $^{(7,9-11,16,18,19)}$ evolved with pathological fracture after or during diagnostic investigation. In all of these cases, the tumor was present in the femur, four diaphyseal $(7,11,16,17)$ and one located in the distal region of the femur..$^{(9)}$

The most common locations for intraosseous RMS are femoral diaphysis. ${ }^{(2,7,12,17,18)}$ followed for diffuse 


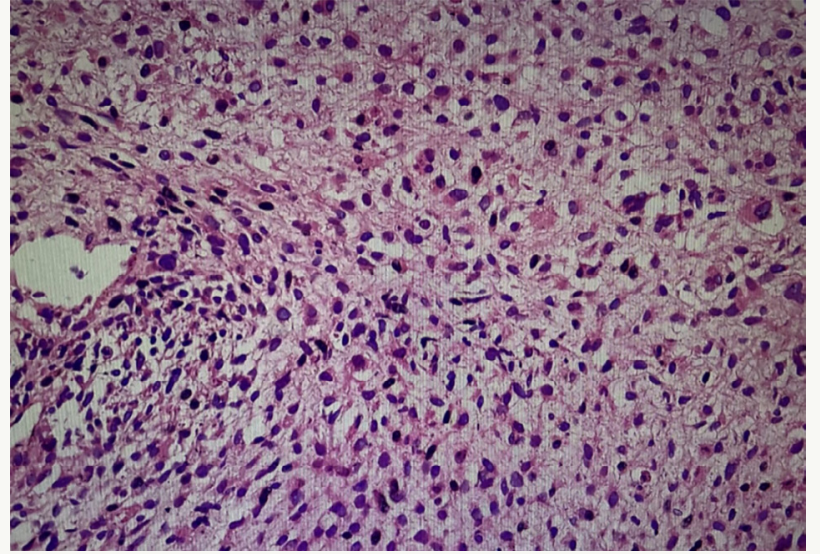

Figure 3. Hematoxylin-eosin (H\&E) stain (low and high power).

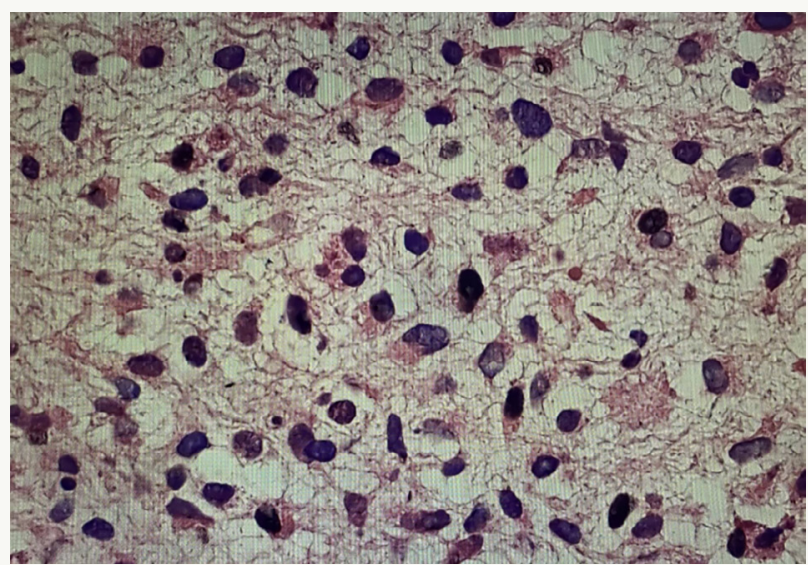

Figure 4. Hematoxylin-eosin (H\&E) stain (low and high power).

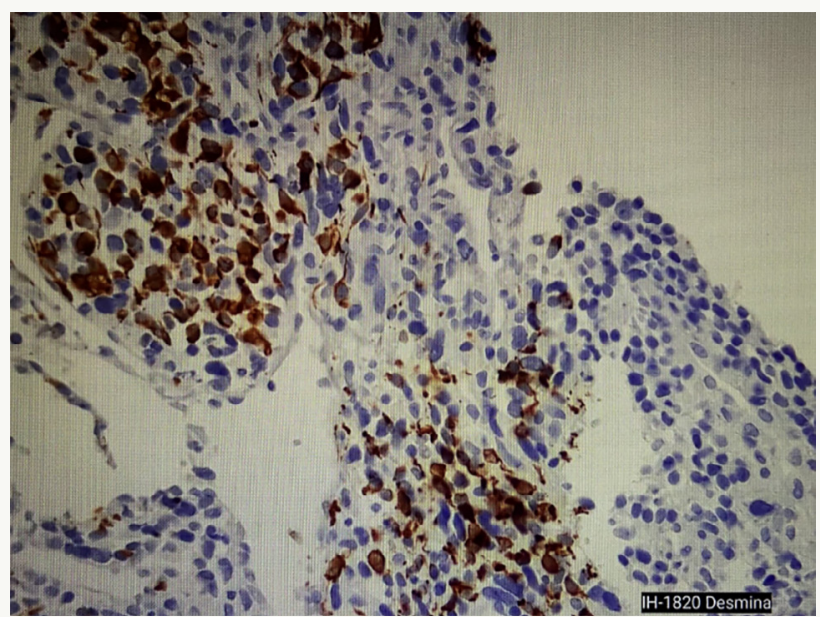

Figure 5. Immunohistochemistry slide showing strong cytoplasmatic and focal reactivity (desmine).

involvement of bone.(1,5,10) Other cases reported showed up on the distal femur, ${ }^{(9)}$ proximal femur, ${ }^{(18)}$ proximal fibula, ${ }^{(11)}$ sacrum, $^{(6)}$ iliac, $^{(14)}$ and humerus. ${ }^{(17)}$ Osteolytic lesions were the main pattern, $(2,11,17)$ followed by permeated infiltration, eventually associated with some soft tissue component.

Like our reported case, the misdiagnosis has occurred in six cases..$^{(1,7,9-12)}$ In 3 patients ${ }^{(7,9,11)}$ we identified that an initial chemotherapy treatment protocol was performed for another disease, just as it hap-

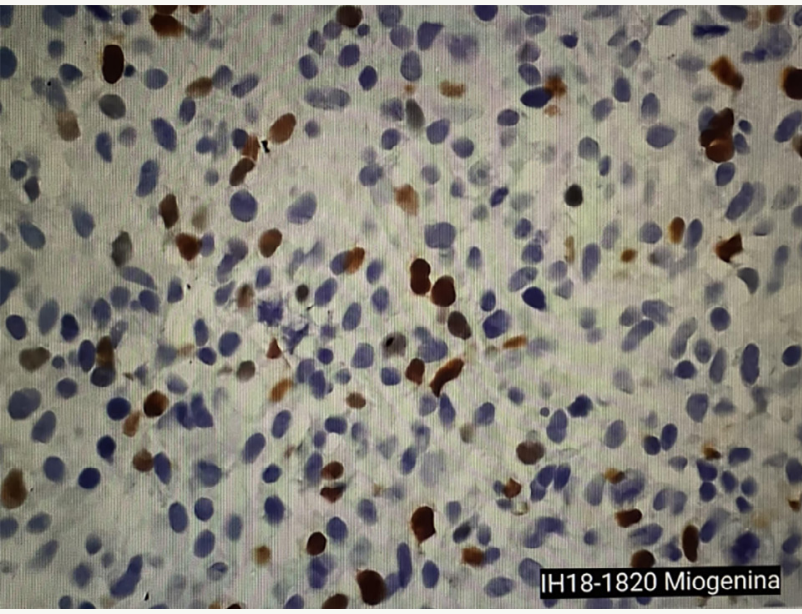

Figure 6. Immunohistochemistry slide showing strong nuclear and focal reactivity (miogenine).

Table 1. Immunohistochemistry panel with an expression of desmine and myogenine.

\begin{tabular}{lc}
\hline Antigen & Result \\
\hline Desmine & Positive \\
Myogenine & Positive \\
HHF35 & Focal positive \\
CD99 & Positive \\
FLI-1 & Positive \\
Enolase & Positive \\
Chromogranin & Negative \\
AE1AE3 & Positive - rare cells \\
Ki-67 & Positive in 60-70\% \\
\hline
\end{tabular}

pened with our patient. All these cases were initially diagnosed as osteosarcoma. One of them did not receive neoadjuvant chemotherapy. ${ }^{(10)}$

We observed that the protocol initially used (doxorubicin, cisplatin, and methotrexate) differs from the classic rhabdomyosarcoma protocol (vincristine, actinomycin, and cyclophosphamide).(2) Despite it, the protocol has had some effectiveness. The report of the postoperative specimen showed more than 90\% of tumor necrosis. In addition, the consolidation of local treatment with radiotherapy was carried out, as recommended by the European and American protocols for the treatment of rhabdomyosarcoma. ${ }^{(2)}$

The effectiveness of these first chemotherapy regimens could be explained by the effect of doxorubicin in the rhabdomyosarcoma. Doxorubicin has a controversial role in rhabdomyosarcoma treatment regimens, but some studies have put it in protocols for adults and children.(20-22) In this case reported it could explain the partial initial response to osteosarcoma chemotherapy protocol.

There are no reports of local recurrence in the literature, but 6 patients died due to illness. ${ }^{(6,7,12,16,17)}$ The heterogeneity of the information in the differ- 
Table 2. Relation of previous case reports about bone RMS.

\begin{tabular}{|c|c|c|c|c|}
\hline & Age (years) & Gender & Site & Classification \\
\hline Pasquel et al. (1976) ${ }^{(15)}$ & 13 & Female & Femur - Diaphysis & ERMS \\
\hline Hsueh et al. (1986) ${ }^{(9)}$ & 11 & Male & Distal femur & ERMS \\
\hline Oda et al. (1993) $)^{(14)}$ & 32 & Male & Iliac bone & ERMS \\
\hline Lamovec et al. (1994) & 31 & Male & Tibia & Pleomorphic RMS \\
\hline Rashid et al. (1994)(16) & 68 & Female & Femur - diaphysis & Pleomorphic RMS \\
\hline Thomas et al. $(2002)^{(17)}$ & 22 & Male & Humerus & NA \\
\hline Lucas et al. (1996) $)^{(13)}$ & 7 & Female & Femur - diaphysis & ERMS \\
\hline Wang et al. (2000)(18) & 46 & Male & Proximal femur & Pleomorphic RMS \\
\hline Kordek et al. (2007)(11) & 21 & Male & Proximal fibula & RMS (no subtype) \\
\hline Hakozaki et al. $(2008)^{(6)}$ & 16 & Female & Sacrum & ARMS \\
\hline Karagiannis et al. (2015)(10) & 61 & Female & Diffuse - Bone marrow & ARMS \\
\hline Bressner et al. (2016)(7) & 34 & Male & Femur - diaphysis & Pleomorphic RMS \\
\hline Balogh et al. (2016)(1) & 17 & Male & Diffuse - Bone marrow & ARMS \\
\hline Balogh et al. (2016)(1) & 9 & Male & Diffuse - Bone marrow & ARMS \\
\hline
\end{tabular}

ent reports makes impossible to stratify prognostic groups. However, our review carried out suggests that intraosseous rhabdomyosarcoma has a worse prognosis than soft tissue RMS. We understand that this point deserves further study with a more standardized assessment of cases.

The differential diagnosis deserves the main attention in the intraosseous RMS. Despite being the most common soft tissue tumor in children, rhabdomyosarcoma has a rare intraosseous incidence. The most prevalent differential diagnoses were tumors of the Ewing family, ${ }^{(7,10)}$ lymphoproliferative diseases, ${ }^{(1,10)}$ and osteosarcoma. ${ }^{(5,9,11)}$

Its diagnosis depends on a high clinical suspicion, properly staging with imaging tests and, mainly, carry on the specific immunohistochemical research. The doctors (usually orthopedists and oncologists) involved in the treatment must keep it in mind to suggest the diagnostic hypothesis and conduct the case in a multi-professional manner, with discussion with the radiology and pathology team.

Like other sarcomas, the early diagnosis and multimodal approach, satisfactory local control with free margins, chemotherapy, and radiotherapy are essential conditions for its therapeutic success.

\section{REFERENCES}

1. Balogh $P$, Bánusz R, Csóka M, Váradi Z, Varga $E$, Sápi Z. Primary alveolar rhabdomyosarcoma of the bone: two cases and review of the literature. Diagn Pathol. 2016;11(1):99. DOI: https://doi. org/10.1186/s13000-016-0552-9

2. Dasgupta R, Fuchs J, Rodeberg D. Rhabdomyosarcoma. Semin Pediatr Surg. 2016 Oct;25(5):276-83. DOI: https://doi.org/10.1053/j. sempedsurg.2016.09.011
3. Dziuba I, Kurzawa P, Dopierała M, Larque $A B$, Januszkiewicz-Lewandowska D. Rhabdomyosarcoma in children - current pathologic and molecular classification. Pol J Pathol. 2018 May;69(1):20-32. DOI: https://doi.org/10.5114/ pjp.2018.75333

4. World Health Organization (WHO). Classification of tumours of soft tissue and bone. Geneva: WHO; 2013.

5. Dagher R, Helman L. Rhabdomyosarcoma: an overview. Oncologist. 1999;4(1):34-44.

6. Hakozaki M, Hojo H, Kuze T, Tajino T, Yamada $\mathrm{H}$, Kikuta A, et al. Primary rhabdomyosarcoma of the sacrum: a case report and review of the literature. Skeletal Radiol. 2008 Jul;37(7):683-7. DOI: https://doi.org/10.1007/s00256-008-0472-1

7. Bressner JA, Mccarthy EF, Fayad LM, Morris CD. Primary rhabdomyosarcoma of the distal femoral diaphysis: a case report and review of the literature. Skeletal Radiol. 2016 Jul;45(10):1391-5. DOI: https://doi.org/10.1007/s00256-016-2430-7

8. Petrilli AS, Camargo B, Odone Filho V, Bruniera P, Brunetto $A L$, Jesus-Garcia $R$, et al. Results of the Brazilian osteosarcoma treatment group studies III and IV: prognostic factors and impact on survival. J Clin Oncol. 2006 Mar;24(7):1161-8.

9. Hsueh S, Hsih SN, Kuo TT. Primary rhabdomyosarcoma of long bone. A case report. Orthopedics. 1986 May;9(5):705-7.

10. Karagiannis P, Guth N, Thoennissen GB, Bern C, Sperveslage J, Oschlies I, et al. Alveolar rhabdomyosarcoma confined to the bone marrow with no identifiable primary tumour using FDG-PET/ CT. Clin Sarcoma Res. 2015 Nov;5(1):24. DOI: https://doi.org/10.1186/s13569-015-0039-6 
11. Kordek R, Sowa P, Panasiuk M, Kmieciak M, Chudobinski C, Pluciennik E, et al. Primary osseous rhabdomyosarcoma with focal matrix formation mimicking osteosarcoma. Pathol Res Pract. 2007 Dec;203(12):873-7. DOI: https://doi. org/10.1016/j.prp.2007.08.003

12. Lamovec J, Zidar A, Brako M, Golouh R. Primary bone sarcoma with phabdomycosarcomatous component. Pathol Res Pract. 1994 Jan;190(1):51-60. DOI: https://doi.org/10.1016/ s0344-0338(11)80496-6

13. Lucas DR, Ryan JR, Zalupski MM, Gross ML, Ravindranath $\mathrm{Y}$, Ortman B. Primary embryonal rhabdomyosarcoma of long bone. Case report and review of the literature. Am J Surg Pathol. 1996;20:239-44.

14. Oda $Y$, Tsuneyoshi $M$, Hashimoto $H$, Iwashita T, Ushijima M, Masuda S, et al. Primary rhabdomyosarcoma of the iliac bone in an adult: a case mimicking fibrosarcoma. Virchows Arch A Pathol Anat Histopathol. 1993;423(1):65-9.

15. Pasquel PM, Levet SN, De Leon B. Primary rhabdomyosarcoma of bone. A case report. J Bone Joint Surg Am. 1976 Dec;58(8):1176-8.

16. Rashid A, Dickersin GR, Rosenthal DI, Mankin H, Rosenberg AE. Rhabdomyosarcoma of the long bone in an adult. A case report and literature review. Int J Surg Pathol. 1994;1:253-60.
17. Thomas F, Lipton JF, Barbera C, Vigorita VJ, Bryk E. Primary rhabdomyosarcoma of the humerus. A case report and review of the literature. J Bone Joint Surg Am. 2002;84:813-7.

18. Wang JW, Eng $\mathrm{HL}$, Huang $\mathrm{CH}$. Primary rhabdomyosarcoma of long bone. A case report. Clin Orthop Relat Res. 2000 Aug;(377):205-9.

19. Dashti NK, Wehrs RN, Thomas BC, Nair A, Davila J, Buckner JC, et al. Spindle cell rhabdomyosarcoma of bone with FUS-TFCP2 fusion: confirmation of a very recently described rhabdomyosarcoma subtype. Histopathology. 2018 Sep;73(3):514-20.

20. Arndt CAS. Role of doxorubicin in rhabdomyosarcoma: is the answer knowable?. Am Soc Clin Oncol Educ Book. 2012;621-3.

21. Bergeron $C$, Thiesse $P$, Rey A, Orbach D, Boutard $P$, Thomas $C$, et al. Revisiting the role of doxorubicin in the treatment of rhabdomyosarcoma: an up-front window study in newly diagnosed children with high-risk metastatic disease. Eur J Cancer. 2008 Feb;44(3):427-31.

22. Sandler E, Lyden E, Ruymann F, Maurer H, Wharam $M$, Parham D, et al. Efficacy of ifosfamide and doxorubicin given as a phase II "window" in children with newly diagnosed metastatic rhabdomyosarcoma: a report from the Intergroup Rhabdomyosarcoma Study Group. Med Pediatr Oncol. 2001 Nov;37(5):442-8. 